\title{
Risk-factor differences for nonsuicidal self-injury and suicide attempts in Mexican psychiatric patients
}

This article was published in the following Dove Press journal:

Neuropsychiatric Disease and Treatment

5 July 2016

Number of times this article has been viewed

\author{
Ana Fresán' \\ Beatriz Camarena ${ }^{2}$ \\ Thelma Beatriz González- \\ Castro $^{3}$ \\ Carlos Alfonso Tovilla- \\ Zárate $^{4}$ \\ Isela E Juárez-Rojop ${ }^{5}$ \\ Lilia López-Narváez ${ }^{5}$ \\ Alicia E González-Ramón ${ }^{4}$ \\ Yazmín Hernández-Díaz \\ 'Subdirección de Investigaciones \\ Clínicas, Instituto Nacional de \\ Psiquiatría Ramón de la Fuente \\ Muñiz, México City, ${ }^{2}$ Departamento \\ de Genética Psiquiátrica, Instituto \\ Nacional de Psiquiatría Ramón \\ de la Fuente Muñiz, México City, \\ ${ }^{3}$ División Académica Multidisciplinaria \\ de Jalpa de Méndez, Universidad \\ Juárez Autónoma de Tabasco, Jalpa \\ de Méndez, ${ }^{4}$ División Académica \\ Multidisciplinaria de Comalcalco, \\ Universidad Juárez Autónoma de \\ Tabasco, Comalcalco, ${ }^{5} \mathrm{Hospital}$ \\ General de Yajalón, Secretaría de \\ Salud, Yajalón, Chiapas, México
}

Correspondence: Carlos Alfonso Tovilla-Zárate

División Académica Multidisciplinaria de Comalcalco, Universidad Juárez Autónoma de Tabasco, Ranchería Sur, Cuarta Sección, Comalcalco, Tabasco 86650, Mexico

Tel +52 993358 I500 ext 690 I

Email alfonso_tovillaz@yahoo.com.mx
Background: The present study compared sociodemographic characteristics, comorbidities with substance use, and impulsivity features in three groups of psychiatric patients - suicide attempters, nonsuicidal self-injury, and nonsuicidal without self-injury - to determine the predictive factors for nonsuicidal self-injury or suicide behavior.

Patients and methods: Demographic features and self-reported substance use were assessed in 384 Mexican psychiatric patients. Impulsivity features were evaluated using the Plutchik Impulsivity Scale. Comparison analyses between groups were performed and a logistic regression model used to determine the factors associated with nonsuicidal with self-injury behavior and suicidal behavior.

Results: Different predictive factors were observed for nonsuicidal self-injury and suicidal behavior. Females were more likely to present nonsuicidal self-injury behaviors (odds ratio [OR] $0.42,95 \%$ confidence interval [CI] $0.18-0.93 ; P=0.03$ ). For suicide attempters, the factors associated were younger age (OR $0.89,95 \%$ CI $0.85-0.93 ; P<0.001)$, less than 6 years of schooling (OR $0.2,95 \%$ CI 0.06-0.6; $P=0.004)$, and higher impulsivity traits, such as self-control (OR 1.19, 95\% CI 1.03-1.36; $P=0.01$ ), planning of future actions (OR 0.79, 95\% CI 0.66-0.95; $P=0.01$ ), and physiological behavior (OR 1.34, 95\% CI 1.01-1.78; $P=0.03$ ).

Conclusion: Our results show that in a Mexican population, impulsivity features are predictors for suicide attempts, but not for self-injury. Other factors related to sociocultural background and individual features (such as personality) may be involved in this behavioral distinction, and should be studied in future research aimed at better understanding of both self-harmful behaviors.

Keywords: suicide, impulsivity, Mexican population, self-injury

\section{Introduction}

Suicidal behavior (SB) has been established as an important issue on which several researchers have focused their investigations. ${ }^{1,2}$ With the recent distinction between nonsuicidal self-injury (NSSI) and suicide attempt (SA), the NSSI disorder has become an important new line for research. ${ }^{3-5}$ NSSI is defined as a disorder where the individual causes himself or herself deliberate tissue damage but without the intention to die, while in SA there is at least some intent to die; therefore, intentionality is an important matter for diagnosis. ${ }^{6-8}$ The growing interest of this topic suggests that NSSI is one of the most robust prospective predictors for suicidal ideation or attempts, ${ }^{9-11}$ as individuals with NSSI frequently report emotional dysregulation. ${ }^{8,12}$ Consequently, self-injury has been related to psychiatric disorders, such as impulsivity, anxiety, depression, schizophrenia, and SB. ${ }^{13-16}$ One of the most common psychiatric symptoms studied in relation to NSSI is impulsivity, as it has been related to the predisposition toward rapid, unplanned reactions to internal or external stimuli, regardless of the negative consequences of their actions to themselves or others. ${ }^{3,17}$ Clinical experience and some studies suggest that 
impulsiveness is correlated with the severity and frequency of NSSI; ${ }^{12,18}$ therefore, some researchers have suggested that the measurement of impulsivity in psychiatric patients may provide a better understanding of NSSI. ${ }^{19,20}$ Nowadays, there are several scales and clinical interviews useful in the assessment of SB and NSSI; nevertheless, in daily clinical practice, clinicians require a functional identification of some risk factors that may distinguish clear suicidal intention from self-injury behavior during the first interview with the patient. Therefore, the aim of the present study was to compare sociodemographics, substance-use comorbidities, and impulsivity features in three groups of psychiatric patients - SA, NSSI, and nonsuicidal without self-injury (NS) - and to determine the predictive factors for NSSI or SA behavior.

\section{Patients and methods}

\section{Sample}

All subjects signed a written informed consent to participate in the study. The study was approved by the ethics committee of the General Hospital of Comalcalco. A total of 318 psychiatric patients were consecutively recruited from November 2012 to September 2013 from the outpatient service of the General Hospital of Comalcalco, Tabasco, Mexico (105 patients) and the Instituto Nacional de Psiquiatria Ramón de la Fuente Muñíz (INPRF) in Mexico City (213 patients).

Patients from the General Hospital of Comalcalco were enrolled from the outpatient services of psychiatry at the hospital; the patients included presented at least one psychiatric diagnosis according to their clinical chart, confirmed by the physician at the clinic. On the other hand, patients from the INPRF were enrolled from ongoing research protocols (as this is a highly specialized mental health center dedicated to research, education, and treatment of psychiatric patients) aimed at assessing impulsivity traits in mood, psychotic, and stress-related disorders.

At both sites, a clinical interview was completed with the patient and his or her relatives, then a trained clinician or researcher confirmed the diagnosis using the Structured Clinical Interview for DSM-IV Axis I Disorders. ${ }^{21}$ Patients were stratified into SA, NSSI, and NS groups in accordance with the clinical chart of each patient, the clinical consensus between treating physicians and clinical researchers of the present study, and following the definitions for each group.

\section{Suicide attempters}

We defined SA as a self-harm behavior with at least some intent to end one's own life. This group included SA patients.
Only unrelated patients (with no family relationship) were included.

\section{Nonsuicidal self-injury patients}

Patients in this group had a history of NSSI behavior. The inclusion criteria for this group comprised the absence of SAs and that the patient had incurred self-injury on at least five different occasions in the last year prior to their inclusion in this study. Following the reports in the literature, we defined self-injury as a nonfatal act that results in bodily injury executed without the intent to die. ${ }^{22,23}$

\section{Nonsuicidal without self-injury patients}

A group of psychiatric patients without a history of SAs or self-injury was included as a control.

\section{Assessment procedure}

Demographic data and comorbidity with substance use were collected from medical records and a direct clinical interview recorded in a previously designed format. All participants completed the impulsivity measurements during a follow-up consultation at either of the two institutions. Tests were completed between 8 am and 3 pm. For the impulsivity assessment, we used the Plutchik Impulsivity Scale in Spanish (designed to measure the tendency of a subject to engage in impulsive, spur-of-the-moment behaviors that reflect possible loss of control), ${ }^{24}$ which is a self-administered questionnaire comprising 15 items scored on a 4-point Likert scale (0-4 points). According to a factor analysis performed in Mexican psychiatric patients, the main areas of impulsivity rated by the scale are: 1) self-control, which assesses the capacity of the subject to wait or delay his/her actions; 2) planning of future actions, which addresses the possibility of a person to realize the consequences of his/her actions and to persevere with his/her ideas; 3) physiological behaviors, which evaluates impulsivity in eating and sexual behaviors; and 4) spontaneous behavior, which evaluates thoughtless and uncontrolled behavior. The total score of the scale is obtained by the sum of all item scores. ${ }^{25,26}$ The Spanish version showed adequate internal consistency for its use in clinical research. ${ }^{26}$

\section{Statistical analysis}

The analyses were performed using SPSS 20.0. Demographic and clinical characteristics were expressed as frequencies and percentages for categorical variables and as mean and standard deviations for continuous variables. The initial comparison between patients and control subjects was analyzed 
using $\chi^{2}$ tests for categorical variables and independent samples, while $t$-tests were used for continuous variables. For the group analyses (SA, NSSI, NS groups), analysis of variance followed by Bonferroni correction were performed. Second, logistic regression analyses were performed, including demographic characteristics, comorbidity with substance use, and impulsivity traits as explanatory variables. Finally, the patient connection to the SA or NSSI groups was the outcome variable. Regression coefficients $(\beta)$, standard deviations of $\beta$, odds ratio and $95 \%$ confidence intervals were also calculated. Significance was set at $P<0.05$; to address multiple comparisons, the significance level for Bonferroni testing was established at $P=0.016(0.05 \div 3)$.

\section{Results}

\section{Demographic characteristics}

Based on SB history, 90 patients $(28.3 \%)$ were classified as NSSI, 155 (48.7\%) as SA, and $73(23 \%)$ as NS. Significant differences emerged between groups in terms of demographics, substance-use comorbidity, and psychiatric diagnoses

(Table 1). NS patients were predominantly male and older when compared to NSSI and SA patients. SA patients were more frequently single with a lower level of education. More patients in the NSSI group reported substance use when compared to the SA and NS groups. Mood disorders were more frequent in the SA and NSSI groups.

\section{Impulsivity features}

Comparison of groups using Plutchik Impulsivity Scale subscales and total scores are shown in Table 2. In accordance with post hoc comparisons, SA patients and NSSI patients reported similar levels of impulsivity features, which in general were higher than those reported in NS patients. The "planning of future actions" subscale was the only scale where NSSI patients exhibited higher scores when compared to the SA and NS groups, the latter reporting similar scores.

\section{Logistic regression analysis}

The logistic regression models included demographic variables, substance use, and impulsivity features as explanatory variables, with the pertinent group (SA or NSSI) as

Table I Prevalence of descriptive characteristics and psychiatric diagnosis of suicide assessment in a Mexican population

\begin{tabular}{|c|c|c|c|c|c|}
\hline Sociodemographics & $\begin{array}{l}\text { NSSI } \\
n=90(\%)\end{array}$ & $\begin{array}{l}\text { SA } \\
n=155(\%)\end{array}$ & $\begin{array}{l}\text { NS } \\
n=73(\%)\end{array}$ & $\chi^{2} / F$ & P-value \\
\hline Age & 29.68 (8.59) & $25.82(8.88)$ & $32.44(9.72)$ & 14.6 & $<0.001$ \\
\hline \multicolumn{6}{|l|}{ Sex } \\
\hline Male & $23(25.6)$ & 45 (29) & 35 (47.9) & 10.78 & 0.005 \\
\hline Female & $67(74.4)$ & $110(7 I)$ & $38(52.1)$ & & \\
\hline \multicolumn{6}{|l|}{ Marital status } \\
\hline Married & $36(40)$ & $62(40)$ & $25(34.2)$ & 13.22 & 0.04 \\
\hline Single & 44 (48.9) & $88(56.8)$ & $37(50.7)$ & & \\
\hline Widowed & 0 & 0 & I (I.4) & & \\
\hline Separated/divorced & $10(I I . I)$ & $5(3.2)$ & $10(13.7)$ & & \\
\hline \multicolumn{6}{|l|}{ Education } \\
\hline$<6$ years of schooling & $7(7.8)$ & $38(24.5)$ & $7(9.6)$ & 14.83 & 0.001 \\
\hline$>6$ years of schooling & $83(92.2)$ & I I 7 (75.5) & $66(90.4)$ & & \\
\hline \multicolumn{6}{|l|}{ Comorbidities } \\
\hline \multicolumn{6}{|l|}{ Alcohol } \\
\hline Yes & $54(60)$ & $54(34.8)$ & $30(4 I . I)$ & 14.87 & 0.001 \\
\hline No & $36(40)$ & IOI (65.2) & $43(58.9)$ & & \\
\hline \multicolumn{6}{|l|}{ Cannabis use } \\
\hline Yes & $28(31.1)$ & $20(12.9)$ & $9(12.3)$ & 14.84 & 0.001 \\
\hline No & $62(68.9)$ & I 35 (87.I) & 64 (87.7) & & \\
\hline \multicolumn{6}{|l|}{ Cigarette smoking } \\
\hline Yes & $5 \mathrm{I}(56.7)$ & $27(17.4)$ & $21(28.8)$ & 41.12 & $<0.001$ \\
\hline No & $39(43.3)$ & $128(82.6)$ & $52(7 \mid .2)$ & & \\
\hline \multicolumn{6}{|l|}{ Psychiatric disorders } \\
\hline Schizophrenia and psychosis & $20(22.2)$ & $13(8.9)$ & $31(42.5)$ & 94.43 & $<0.001$ \\
\hline Mood disorders & $43(47.8)$ & $79(54.1)$ & $27(37)$ & & \\
\hline Stress-related disorders & $9(10)$ & $36(24.7)$ & $15(20.5)$ & & \\
\hline Substance-related disorders & I (I.I) & $18(12.3)$ & 0 & & \\
\hline Personality disorder & 17 (I8.9) & 0 & 0 & & \\
\hline
\end{tabular}

Abbreviations: NSSI, nonsuicidal self-injury; SA, suicide attempt; NS, nonsuicidal without self-injury. 
Table 2 Comparison of impulsivity dimensions among psychiatric groups

\begin{tabular}{|c|c|c|c|c|c|c|c|c|}
\hline \multirow[t]{2}{*}{$n=318$} & \multirow{2}{*}{$\begin{array}{l}\begin{array}{l}\text { Nonsuicidal } \\
\text { self-injury } \\
(n=90)\end{array} \\
\text { Mean (SD) }\end{array}$} & \multirow{2}{*}{$\begin{array}{l}\begin{array}{l}\text { Suicide } \\
\text { attempters } \\
(\mathrm{n}=155)\end{array} \\
\text { Mean (SD) }\end{array}$} & \multirow{2}{*}{$\begin{array}{l}\text { Nonsuicidal, } \\
\text { not self-injury } \\
(\mathrm{n}=73) \\
\text { Mean (SD) }\end{array}$} & \multicolumn{2}{|c|}{ Statistic } & \multicolumn{3}{|c|}{$\begin{array}{l}\text { Post hoc comparison P-value } \\
\text { (mean difference) }\end{array}$} \\
\hline & & & & $\boldsymbol{F}$ & $P$-value & SA vs NSSI & SA vs NS & NSSI vs NS \\
\hline Self-control & $10.6(3.87)$ & $10.08(3.78)$ & $7.55(4.17)$ & 14.17 & $<0.00 \mathrm{I}$ & $0.94(-0.52)$ & $<0.001(2.52)$ & $<0.001(3.05)$ \\
\hline Planning of future actions & $6.77(2.52)$ & $5.63(2.12)$ & $5.59(2.23)$ & 8.33 & $<0.00 \mathrm{I}$ & $0.001(-1.14)$ & I $(0.03)$ & $0.003(1.18)$ \\
\hline Physiological behavior & $2.34(1.74)$ & $2.4 I(I .7)$ & $1.42(1.25)$ & 9.86 & $<0.001$ & $\mathrm{I}(0.06)$ & $<0.001(0.98)$ & $0.001(0.92)$ \\
\hline Spontaneous behavior & $5.2(2.28)$ & $5.07(1.91)$ & $3.64(1.93)$ & 14.88 & $<0.001$ & I $(-0.12)$ & $<0.001(1.42)$ & $<0.001(1.55)$ \\
\hline Total impulsivity & $24.91(8.06)$ & $23.21(7.35)$ & $|8.2|(7.04)$ & 17.33 & $<0.001$ & $0.26(-1.69)$ & $<0.001(5)$ & $<0.001$ (6.7) \\
\hline
\end{tabular}

Abbreviations: SD, standard deviation; SA, suicide attempt; NSSI, nonsuicidal self-injury; NS, nonsuicidal without self-injury.

the outcome using the control group (NS) as reference. For the first analysis - for the prediction of NSSI behavior - the logistic regression model correctly classified $71.8 \%$ of the cases, being much more precise in classifying patients with self-injury behaviors (75.6\%) than control subjects (67.1\%). This model is considered a valid construct in accordance to the Hosmer-Lemeshow test $(P=0.43)$. The only significant predictor for this model was sex, where male subjects were $42 \%$ less likely to exhibit NSSI behavior than females (Table 3).

In a second logistic model (finding the significant predictors for SAs), we found that some demographic features, such as being male and being older, were protective factors for SAs, while higher-impulsivity traits were risk factors. This model was highly precise for classifying SA patients (90.3\%) compared to control subjects $(54.8 \%)$ with an adequate theoretical construct according to the Hosmer-Lemeshow test $(P=0.64)$ (Table 4).

\section{Discussion}

The aim of the present study was to compare sociodemographic characteristics, comorbidity with substance use, and impulsivity features in three groups of psychiatric

Table 3 Summary of multiple regression analysis predicting non suicidal with self-injury

\begin{tabular}{|c|c|c|c|c|c|}
\hline & $\beta$ & SE $\beta$ & $\begin{array}{l}\text { Odds } \\
\text { ratio }\end{array}$ & $95 \% \mathrm{Cl}$ & $P$-value \\
\hline Age & -0.03 & 0.02 & 0.96 & $0.92-1.08$ & 0.11 \\
\hline Sex & -0.86 & 0.4 & 0.42 & $0.18-0.93$ & 0.03 \\
\hline Education & -0.58 & 0.66 & 0.56 & $0.15-2.05$ & 0.38 \\
\hline Alcohol & -0.03 & 0.49 & 0.96 & $0.36-2.51$ & 0.93 \\
\hline Cannabis use & 0.73 & 0.54 & 2.08 & $0.71-6.09$ & 0.17 \\
\hline Cigarette smoking & 0.87 & 0.5 & 2.4 & $0.9-6.39$ & 0.08 \\
\hline Self-control & 0.05 & 0.06 & 1.05 & $0.92-1.2$ & 0.39 \\
\hline Planning of future actions & 0.11 & 0.08 & 1.12 & $0.93-1.32$ & 0.14 \\
\hline Physiological behavioral & 0.17 & 0.14 & 1.19 & $0.89-1.59$ & 0.22 \\
\hline Spontaneous behavior & 0.08 & 0.12 & 1.08 & $0.84-1.39$ & 0.52 \\
\hline
\end{tabular}

Abbreviations: $\mathrm{SE}$, standard error; $\mathrm{Cl}$, confidence interval. patients - SA, NSSI, and NS - and to determine the predictive factors for NSSI or SB.

\section{Comparison of sociodemographics, comorbidities, and impulsivity features}

When we analyzed the sociodemographic characteristics of psychiatric patients, it was observed that females more frequently present self-injury or SB than men. Some studies support these findings, eg, Sahlin et al and In-Albon et al observed that females engage more frequently in NSSI than males. ${ }^{27,28}$ One possible explanation for this tendency is that females are frequently seen in more vulnerable situations (eg, show poor social problem-solving), which predisposes them to respond to stressful events with affective dysregulation, developing a need to use an NSSI or other behavior as an SA that helps them cope with the stressful experiences. ${ }^{28-30}$

Interestingly enough, our samples presented a higher level of education (over 6 years), the reason for which could be that frequently some individuals are not able to tolerate sociocultural demands (eg, the expectations of the family) and can only regulate themselves with self-injury or SAs. ${ }^{5,27}$

As expected, we found that impulsivity traits were higher in patients with a history of SAs. ${ }^{31}$ Some authors consider

Table 4 Summary of multiple regression analysis predicting suicide attempts

\begin{tabular}{|c|c|c|c|c|c|}
\hline & $\beta$ & SE $\beta$ & $\begin{array}{l}\text { Odds } \\
\text { ratio }\end{array}$ & $95 \% \mathrm{Cl}$ & P-value \\
\hline Age & -0.1 & 0.02 & 0.89 & $0.85-0.93$ & $<0.001$ \\
\hline Sex & -0.51 & 0.38 & 0.59 & $0.28-1.26$ & 0.17 \\
\hline Education & -1.59 & 0.56 & 0.2 & $1.64-14.88$ & 0.004 \\
\hline Alcohol & -1.59 & 0.53 & 1.99 & $0.70-5.64$ & 0.19 \\
\hline Cannabis use & 0.51 & 0.62 & 1.68 & $0.49-5.66$ & 0.4 \\
\hline Cigarette smoking & -0.48 & 0.54 & 0.61 & $0.21-1.78$ & 0.37 \\
\hline Self-control & 0.17 & 0.7 & 1.19 & $1.03-1.36$ & 0.01 \\
\hline Planning of future actions & -0.22 & 0.9 & 0.79 & $0.66-0.95$ & 0.01 \\
\hline Physiological behavioral & 0.29 & 0.14 & $\mathrm{I} .34$ & $1.01-1.78$ & 0.03 \\
\hline Spontaneous behavior & 0.14 & 0.13 & 1.15 & $0.89-1.50$ & 0.27 \\
\hline
\end{tabular}

Abbreviations: SE, standard error; $\mathrm{Cl}$, confidence interval. 
that impulsivity in these patients is related to the decision of SA agents to avoid pain in a quick manner; ${ }^{32,33}$ also, some outcomes propose that some SA subjects take the decision of self-harm quickly or have less self-control. ${ }^{31,33,34}$ Nevertheless, these traits were also high and even of a similar severity in the group with self-injury behaviors. Our results showed that impulsivity was a common factor between SB and NSSI. We want to emphasize that several reports have shown a similar association with a variety of negative mental health issues (such as impulsivity). ${ }^{35-37}$ Some studies suggested that a higher rate of life stressors increases the risk to go through an NSSI period before attempting suicide. ${ }^{38-40}$

\section{Predictive factors for nonsuicidal self- injury or suicidal behavior}

We performed an additional analysis to observe factors associated with NSSI or SB, by evaluating the interaction of demographic characteristics, substance use, and impulsivity. In our analysis, individuals with less than 6 years of school education had a higher probability of presenting SAs, which is consistent with previous reports, ${ }^{41}$ whereas sex was a factor associated with NSSI. ${ }^{42}$

In our impulsivity analysis, self-control, planning of future actions, and physiological behavior emerged as characteristics associated with SB but not NSSI. This outcome supports the theory that it is necessary to include the assessment of multiple risk factors (eg, childhood maltreatment, substance abuse, age, and marital status, among others) to have a greater understanding of the developmental pathways of NSSI and SA engagement. ${ }^{5,43}$ These results show the need for more studies to help increase the understanding of the differences between SB and NSSI and treat them as a similar problem or as separate disorders. ${ }^{44}$

\section{Limitations}

Our findings should be considered within the context of the limitations of the study. First, there was bias related to different sample-selection criteria between the study sites. The inclusion of patients with personality and substancerelated disorders from the General Hospital of Comalcalco represented slightly less than $10 \%$ of the total sample, and may have had an impact on what could be reported of selfharm behaviors in psychiatric patients. Nevertheless, most patients (over $80 \%$ in each group) were diagnosed with mood, psychotic, or stress-related disorders, and our results may be significant for these particular diagnoses. Although this study included psychiatric patients as controls, patients with NSSI, and a group of SA patients, we did not include patients that presented both self-injury and SA; therefore, that group should be included in future studies. Second, the SB evaluated in the study included just attempters, and did not include ideation or the completed suicide; as such, the generalization of SB could be unclear. Also, the NS represented less than a quarter of the sample, and so may not be representative. Nevertheless, it is important to highlight that although psychotic and mood disorders are diagnoses with highly prevalent self-harm behaviors, this particular sample exhibited other important factors (not related to the specificity of diagnosis) more related to the overt manifestation of these harmful behaviors.

Despite these limitations, our results add essential information to the limited existing literature about the association among impulsivity, self-injury, SA, and related risk factors in a Mexican population.

\section{Conclusion}

In conclusion, this study shows that in a Mexican population, impulsivity features between NSSI and SB groups could be similar; however, the main difference was that impulsivity only acted as a predictive factor for SA subjects, but not for NSSI. Therefore, more studies including the life history of the subjects, sociocultural background, individual differences (such as personality), and other comorbidities are necessary for a better understanding of suicide disorders and NSSI. It is necessary to increase the knowledge about these self-harmful behaviors in order to promote their identification and early intervention. Along these lines, it would be possible to reduce their frequency of occurrence, giving people who suffer them an opportunity to improve their quality of life.

\section{Disclosure}

The authors report no conflicts of interest in this work.

\section{References}

1. Hamza CA, Willoughby T, Heffer T. Impulsivity and nonsuicidal selfinjury: a review and meta-analysis. Clin Psychol Rev. 2015;38:13-24.

2. Pérez S, Marco JH, García-Alandete J. Comparison of clinical and demographic characteristics among borderline personality disorder patients with and without suicidal attempts and non-suicidal self-injury behaviors. Psychiatry Res. 2014;220(3):935-940.

3. Anestis MD, Tull MT, Lavender JM, Gratz KL. The mediating role of non-suicidal self-injury in the relationship between impulsivity and suicidal behavior among inpatients receiving treatment for substance use disorders. Psychiatry Res. 2014;218(1-2):166-173.

4. Rodav O, Levy S, Hamdan S. Clinical characteristics and functions of non-suicide self-injury in youth. Eur Psychiatry. 2014;29(8):503-508.

5. Victor SE, Klonsky ED. Correlates of suicide attempts among selfinjurers: a meta-analysis. Clin Psychol Rev. 2014;34(4):282-297.

6. Bresin K, Carter DL, Gordon KH. The relationship between trait impulsivity, negative affective states, and urge for nonsuicidal self-injury: a daily diary study. Psychiatry Res. 2013;205(3):227-231. 
7. García-Nieto R, Blasco-Fontecilla H, de León-Martinez V, Baca-García E. Clinical features associated with suicide attempts versus suicide gestures in an inpatient sample. Arch Suicide Res. 2014;18(4):419-431.

8. Leong CH, Wu AM, Poon MM. Measurement of perceived functions of non-suicidal self-injury for Chinese adolescents. Arch Suicide Res. 2014; 18(2):193-212.

9. Horváth OL, Mészáros G, Balázs J. [Non-suicidal self-injury in adolescents: current issues]. Neuropsychopharmacol Hung. 2015;17(1):14-22. Hungarian.

10. Mullins-Sweatt SN, Lengel GJ, Grant DM. Non-suicidal self-injury: the contribution of general personality functioning. Person Ment Health. 2013;7(1):56-68.

11. Di Pierro R, Sarno I, Perego S, Gallucci M, Madeddu F. Adolescent nonsuicidal self-injury: the effects of personality traits, family relationships and maltreatment on the presence and severity of behaviours. Eur Child Adolesc Psychiatry. 2012;21(9):511-520.

12. Janis IB, Nock MK. Are self-injurers impulsive? Results from two behavioral laboratory studies. Psychiatry Res. 2009;169(3):261-267.

13. McCloskey MS, Look AE, Chen EY, Pajoumand G, Berman ME. Nonsuicidal self-injury: relationship to behavioral and self-rating measures of impulsivity and self-aggression. Suicide Life Threat Behav. 2012; 42(2):197-209.

14. Claes L, Fagundo AB, Jiménez-Murcia S, et al. Is non-suicidal self-injury related to impulsivity in anorexia nervosa? Results from self-report and performance-based tasks. Eur Eat Disord Rev. 2015;23(1):28-33.

15. Black EB, Mildred H. A cross-sectional examination of non-suicidal self-injury, disordered eating, impulsivity, and compulsivity in a sample of adult women. Eat Behav. 2014;15(4):578-581.

16. Lopez-Morinigo JD, Fernandes AC, Chang CK, et al. Suicide completion in secondary mental healthcare: a comparison study between schizophrenia spectrum disorders and all other diagnoses. $B M C$ Psychiatry. 2014;14:213.

17. You J, Lin MP, Leung F. A longitudinal moderated mediation model of nonsuicidal self-injury among adolescents. J Abnorm Child Psychol. 2015;43(2):381-390.

18. Taylor J, Peterson CM, Fischer S. Motivations for self-injury, affect, and impulsivity: a comparison of individuals with current self-injury to individuals with a history of self-injury. Suicide Life Threat Behav. 2012;42(6):602-613.

19. Allen KJ, Hooley JM. Inhibitory control in people who self-injure: evidence for impairment and enhancement. Psychiatry Res. 2015;225(3): 631-637.

20. Sadeh N, Londahl-Shaller EA, Piatigorsky A, et al. Functions of nonsuicidal self-injury in adolescents and young adults with Borderline Personality Disorder symptoms. Psychiatry Res. 2014;216(2):217-222.

21. First M, Spitzer R, Gibbon M, Williams J. Structured Clinical Interview for DSM-IV Axis I Disorders (SCID-I). Clinician version. Washington: American Psychiatric Press; 1996.

22. Dougherty DM, Mathias CW, Marsh-Richard DM, et al. Impulsivity and clinical symptoms among adolescents with non-suicidal self-injury with or without attempted suicide. Psychiatry Res. 2009;169(1):22-27.

23. O’Carroll PW, Berman AL, Maris RW, Moscicki EK, Tanney BL, Silverman MM. Beyond the Tower of Babel: a nomenclature for suicidology. Suicide Life Threat Behav. 1996;26(3):237-252.

24. Plutchik R, Van Praag H. The measurement of suicidality, aggressivity and impulsivity. Prog Neuropsychopharmacol Biol Psychiatry. 1989; 13 Suppl:S23-S34.

25. Lazarevich I, Irigoyen-Camacho ME, Velázquez-Alva MC. Obesity, eating behaviour and mental health among university students in Mexico City. Nutr Hosp. 2013;28(6):1892-1899.
26. Páez F, Jiménez A, López A, Raull Ariza JP, Ortega Soto H, Nicolini H. Validity study of the translation into Spanish of Plutchik's Impulsitivity Scale. [Estudio de validez de la traducción al castellano de la Escala de Impulsividad de Plutchik. Salud Ment (Mex)]. 1996;19(3):10-12.

27. Sahlin-Berg H, Moberg T, Hirvikoski T, Jokinen J. Non-suicidal selfinjury and interpersonal violence in suicide attempters. Arch Suicide Res. 2015;19(4):500-509.

28. In-Albon T, Bürli M, Ruf C, Schmid M. Non-suicidal self-injury and emotion regulation: a review on facial emotion recognition and facial mimicry. Child Adolesc Psychiatry Ment Health. 2013;7(1):5.

29. Hawton K, Harriss L. How often does deliberate self-harm occur relative to each suicide? A study of variations by gender and age. Suicide Life Threat Behav. 2008;38(6):650-660.

30. Fresán A, González-Castro TB, Peralta-Jiménez Y, et al. Gender differences in socio-demographic, clinical characteristics and psychiatric diagnosis in/of suicide attempters in a Mexican population. Acta Neuropsychiatr. 2015;27(3):182-188.

31. Bridge JA, Reynolds B, McBee-Strayer SM, et al. Impulsive aggression, delay discounting, and adolescent suicide attempts: effects of current psychotropic medication use and family history of suicidal behavior. J Child Adolesc Psychopharmacol. 2015;25(2):114-123.

32. Claes L, Bouman WP, Witcomb G, Thurston M, Fernandez-Aranda F, Arcelus J. Non-suicidal self-injury in trans people: associations with psychological symptoms, victimization, interpersonal functioning, and perceived social support. J Sex Med. 2015;12(1):168-179.

33. Oquendo MA. Impulsive versus planned suicide attempts: different phenotypes? J Clin Psychiatry. 2015;76(3):293-294.

34. Vanyukov PM, Szanto K, Siegle GJ, et al. Impulsive traits and unplanned suicide attempts predict exaggerated prefrontal response to angry faces in the elderly. Am J Geriatr Psychiatry. 2015;23(8):829-839.

35. Brausch AM, Decker KM, Hadley AG. Risk of suicidal ideation in adolescents with both self-asphyxial risk-taking behavior and nonsuicidal self-injury. Suicide Life Threat Behav. 2011;41(4):424-434.

36. Jenkins AL, Schmitz MF. The roles of affect dysregulation and positive affect in non-suicidal self-injury. Arch Suicide Res. 2012;16(3): $212-225$.

37. Terada S, Matsumoto Y, Sato T, Okabe N, Kishimoto Y, Uchitomi Y. Suicidal ideation among patients with gender identity disorder. Psychiatry Res. 2011;190(1):159-162.

38. Andover MS, Primack JM, Gibb BE, Pepper CM. An examination of non-suicidal self-injury in men: do men differ from women in basic NSSI characteristics? Arch Suicide Res. 2010;14(1):79-88.

39. Fikke LT, Melinder A, Landro NI. Executive functions are impaired in adolescents engaging in non-suicidal self-injury. Psychol Med. 2011; 41(3):601-610

40. Klonsky ED. Non-suicidal self-injury in United States adults: prevalence, sociodemographics, topography and functions. Psychol Med. 2011; 41(9):1981-1986.

41. Rancāns E, Pulmanis T, Taube M, et al. Prevalence and sociodemographic characteristics of self-reported suicidal behaviours in Latvia in 2010: a population-based study. Nord J Psychiatry. 2016;70(3):195-201.

42. Chartrand H, Bhaskaran J, Sareen J, Katz LY, Bolton JM. Correlates of nonsuicidal self-injury and suicide attempts among tertiary care, emergency department patients. Can J Psychiatry. 2015;60(6):276-283.

43. Liang S, Yan J, Zhang T, et al. Differences between non-suicidal self injury and suicide attempt in Chinese adolescents. Asian J Psychiatr. 2014;8:76-83.

44. Kapur N, Cooper J, O’Connor RC, Hawton K. Non-suicidal self-injury v. attempted suicide: new diagnosis or false dichotomy? Br JPsychiatry. 2013;202(5):326-328. 
Neuropsychiatric Disease and Treatment

Dovepress

\section{Publish your work in this journal}

Neuropsychiatric Disease and Treatment is an international, peerreviewed journal of clinical therapeutics and pharmacology focusing on concise rapid reporting of clinical or pre-clinical studies on a range of neuropsychiatric and neurological disorders. This journal is indexed on PubMed Central, the 'PsycINFO' database and CAS,

and is the official journal of The International Neuropsychiatric Association (INA). The manuscript management system is completely online and includes a very quick and fair peer-review system, which is all easy to use. Visit http://www.dovepress.com/testimonials.php to read real quotes from published authors.

Submit your manuscript here: http://www.dovepress.com/neuropsychiatric-disease-and-treatment-journal 